\section{Perception, risk attitude and willingness to pay for safety and innovative attributes of processed chicken meat in Oyo State, Nigeria}

\author{
Chuks O. Idiaye, ${ }^{1}$ Oluwabunmi A. \\ Ogidan, ${ }^{1}$ Isaac B. Oluwatayo ${ }^{2}$
}

${ }^{1}$ Department of Agricultural Economics, University of Ibadan, Nigeria;

${ }^{2}$ Department of Agricultural Economics and Animal Production, University of Limpopo, South Africa

\begin{abstract}
This paper examined the perception and willingness to pay (WTP) for safety and innovative attributes of processed chicken meat among consumers in Oyo State, Nigeria, taking into consideration their risk attitudes. The study revealed that the majority of the consumers were more aware of existing attributes than innovative attributes of processed chicken meat. Also, the majority of consumers $(73.3 \%)$ were risk-neutral. Only $35 \%$ of respondents had lowered chicken consumption due to safety concerns and about $51.7 \%$ of respondents claimed to be satisfied with the level of safety and quality of chicken meat sold in the Nigerian markets. Sex, household size, major occupation, being a grocery shopper, income and age significantly affected the willingness of consumers to pay a premium for safety and innovative attributes of processed chicken meat. A positive mean WTP of $1,613.16$ Naira was estimated. It was therefore recommended that key players in the value chain should adopt relevant marketing strategies in line with these attributes and target a specific niche of consumers based on their socioeconomic characteristics. Furthermore, government and other regulatory bodies should put measures in place to ensure that processors are sensitized about the safety of chicken.
\end{abstract}

\section{Introduction}

Access to sufficient amounts of safe and nutritious food is critical to sustaining life and ensuring good health. However, global food safety concerns are posing a serious threat to the attainment of good health as well as the Sustainable Development Goal of eradicating food insecurity and hunger across the world. According to the World Health Organisation (WHO), one out of every ten persons in the world falls ill as a result of eating contaminated food while 420, 000 die each year. Children carry $40 \%$ of the burden of food borne diseases with 125, 000 deaths each year (WHO, 2019). Food safety, food and nutritional security are closely linked as unsafe food results in disease and, thus, malnutrition with children and the elderly being among the major victims. Furthermore, this situation puts a heavy burden on healthcare systems, national economies, tourism and trade (WHO, 2019). Therefore, there has arisen a great need for strong collaboration among governments (and their agencies), producers and consumers to ensure food safety.

Food-borne diseases are a major human health problem and occur in both developed and under developed countries. However, due to poor food handling and sanitation practices, inadequate food safety laws, weak regulatory systems, lack of financial resources to invest in safer equipment and lack of education for food-handlers, they are highly prevalent in African countries (Zeru and Kumie, 2007), thereby threatening the nutritional status of the most vulnerable groups in those countries. All this, coupled with urbanization and changes in consumer habits and preferences, has made food safety a front-burner issue in the public domain globally as well as in Africa.

Ensuring food safety is a form of defence against harm to food consumers (Berges et al., 2015) and is a shared responsibility amongst food value chain stakeholders (producers, industry, government and consumers). In most developing nations, the safety of food is compromised due to illiteracy and poverty status of the people (Zeru and Kumie, 2007). In recent times, however, the demand for food has undergone significant changes in Africa and as a result, food safety and quality issues have become more important to developing economies like Nigeria (Berges et al., 2015).

The livestock subsector is very important to the economic development of Nigeria as it contributes about 10 percent to agricultural GDP (CBN, 2010). Poultry alone constitutes more than $60 \%$ of total livestock production in Nigeria, indicating the dominance of the subsector in the livestock industry. Worldwide, consumption surveys indicate that chicken is the second largest consumed meat (FAO, 2010; FAO, 2012; Pattison et al. 2008). Poultry meat accounts for $33 \%$ of global meat consumption serving as the chief meat in the diets of many low to middle income countries (FAO 2012). In Nigeria poultry is the most widely accepted meat without any religious, ethnic or health taboos of the kinds associated with
Correspondence: Isaac Oluwatayo, Department of Agricultural Economics and Animal Production, University of Limpopo, South Africa.

E-mail: isaacoluwatayo@yahoo.com

Key words: Perception; risk attitude; willingness to pay; chicken consumption; food safety.

Contributions: The authors contributed equally.

Conflict of interest: The authors declare no potential conflict of interest.

Funding: None.

Received for publication: 21 August 2019 Revision received: 15 November 2019

Accepted for publication: 24 November 2019.

This work is licensed under a Creative Commons Attribution-NonCommercial 4.0 International License (CC BY-NC 4.0).

C) Copyright: the Author(s), 2020

Licensee PAGEPress, Italy

Italian Journal of Food Safety 2020; 9:8506

doi:10.4081/ijfs.2020.8506

beef or pork (Adeyonu et al., 2016). In recent decades, food safety has become a very important global issue. With at least three million people dying every year from food and water borne diseases (FAO, 2009), it is not surprising how central food safety issues have become to individuals, governments and development organizations.

The influence of globalisation, as well as an interest in maintaining good diet and health in a convenient way, has heightened consumers and retailers' adoption and preference for western style foods with safety and quality attributes (Munene, 2006). In Nigeria, however, the meat industry faces the challenge of fully understanding consumers' and retailers' safety and quality perception of chicken. Knowing this is vital in developing effective differentiation strategies by chicken firms and will consequently induce growth in the meat sector (Bansback, 2014). According to the Food and Agricultural Organization (FAO) of the United Nations, illnesses due to contaminated food are perhaps the most widespread health problem in the contemporary world and an important cause of reduced economic productivity (FAO, 2009). Meat is the main source of food borne illness, which contributes about $20 \%$ of most food safety issues (FAO, 2009). Akunyeli (2008) opined that most developing nations like Nigeria experience a high percentage of sub-standard food consumption. Chicken is the leading source of food borne disease in 
Nigeria; it is the leading culprit in food poisoning, followed closely by beef (Ogundipe et al, 2015). In Nigeria, according to the Centre for Disease Control and Prevention, poultry was the number one source of disease outbreak in 2006. Food Standards Agency posits that $65 \%$ of raw shop-bought chicken is contaminated, largely due to the tendency for poultry and raw beef to harbour pathogenic micro-organisms (FDA, 2007). Despite the acknowledged importance of chicken production to the Nigerian economy and its increased rate of consumption, the safety and quality issues associated with it are alarming. Since 2006, there has been a consistent outbreak of Highly Pathogenic Avian Influencer (HPAI) (commonly known as bird flu) and Newcastle disease which both account for $65 \%$ of poultry losses in Nigeria as well as a number of human deaths making meat safety an issue of intense public concern (Knowles et al., 2007).

Most times poisoned chicken cannot be traced back to farms where they have been produced or processed in other to enact recalls that would help curtail and prevent further disease outbreaks. This is specifically due to a non-existent traceability system, the inability of regulatory bodies to monitor quality and safety standards in chicken meat products and the lack of information dissemination by retailing systems about the safety of chicken. Furthermore, there is a growing concern about the effect of the injudicious and routine use of antibiotics, growth hormones and chemicals in the production, processing, and preservation of chicken, as well as the lack of transparency as to their presence as these could lead to antibiotic resistance in humans among other health crises (FAO, 2009). Chemicals and heavy metals in imported frozen chicken have been discovered to be a causative factor of non-communicable diseases such as cancer, hypertension, and skin disorders.

Despite the presence and activities of national regulatory agencies in Nigeria such as the National Agency for Food and Drug Administration and Control (NAFDAC), Standards Organisation of Nigeria (SON) and the Consumer's Protection Council (CPC) with the mandates to ensure registration compliance, specify standards, regulate production, import, export, sales and testing for standard food and drugs, there is still a major lack of awareness and assurance as to the safety and quality of chicken sold in retail markets. The deplorable sanitary condition of sale outlets, consumers' and retailers' lack of awareness of attributes used as indicators of safe chicken, among other safety concerns, have severely undermined the confidence of many, not only in chicken but in the food industry at large in Nigeria. Furthermore, information asymmetry between value chain players and a lack of incentives for making quality products that will compete with foreign products and satisfy the safety and quality needs of Nigerian consumers has encouraged the increased smuggling of chicken products which has drastically affected the growth of the Nigerian chicken industry. In an attempt to avert this, a ban on imported chicken products was implemented in the year 2000. The ban was meant to enlarge the market share of local producers and to safeguard the health of the masses. However, there has been a mismatch between the high demand for poultry products and their supply due to the low productive capacities of the local industry and its failure to produce safe and quality products that meet international standards due to harsh operating realities. According to the Poultry Association of Nigeria, a supply gap of about 1.2 million tonnes exists in Nigeria's poultry market and much of this gap is usually met through smuggling, leading to losses of around 2.7 billion dollars (399.4 billion) annually. In addition to the above-stated issues, innovativeness, which is another important tool for competition, is sorely lacking in the chicken industry in Nigeria (Iyiola and Oni-Ojo, 2013).

A lot still needs to be done in other to make Nigerian chicken products comparable in safety and quality attributes to foreign products. This can be achieved by looking into specific safety and quality attributes influencing actors' (consumers' and retailers') preference for domestic and imported chicken in other to draw a logical comparison, attain a common ground and develop remedial actions aimed at increasing consumers and retailers' preference for Nigerian chicken meat.

\section{Comparing consumer food safety preferences around the world and Nigeria}

Schroeder et al. (2006) examined the factors influencing purchase decisions for Canadian beef in Canada, the United States, Japan, and Mexico. Their study revealed that consumers considered an array of product attributes. Consumers in all four countries cited product freshness as one of the most important purchase factors. This was followed by leanness, price, and color in Canada and the United States; by country of origin, price, and food safety assurances by consumers in Japan; and by color, price, and flavor by Mexican consumers. Xiang et al. (2012) studied the influence of quality label on consumers' WTP for processed meat in China. The research was also aimed at knowing the role of quality perception, awareness and knowledge on consumers' WTP a premium for Hazard Analysis and Critical Control Points (HACCP) certified processed meat. The results showed that HACCP certification had a significant influence on WTP but consumers' knowledge and awareness of certification had no significant influence on WTP. Similarly, Berges et al., (2015) showed that in Argentina there was a positive WTP for fresh meat attributes such as the presence of a safety certification in the place of purchase, personalized attention at a butcher counter and a bright red color on the product. Lacaze et al. (2009) also showed that Argentinean consumers were willing to pay a premium for organic chicken as a safer option to conventional chicken products. Woolverton and Frimpong (2013), studied consumer demand for domestic and imported broiler meat in urban Ghana in other to evaluate consumers' WTP for non-price attributes of chicken meat. The study revealed that, in addition to price, purchase decisions of consumers were also based on attributes such as origin and freshness. On the other hand, Adeyonu et al., (2016) analyzed the factors influencing consumers' WTP for processed chicken in Kwara State, Nigeria and showed that WTP was more positively related to the socioeconomic characteristics of consumers than to safety attributes.

Although, there are indications that demand for improved chicken quality and safety has been on the rise (FAO, 2010), there is little empirical evidence in Nigeria on the indicators of quality and safety used by consumers in their buying decisions and suppliers in differentiating products to promote sales as well as the extent to which consumers are willing to pay for these attributes. There is scanty literature on the issue of chicken meat safety in Nigeria and this study aimed at filling this gap.

In the light of the foregoing, this paper sought to determine the perception of consumers to existing safety and innovative attributes of chicken, their risk attitude as well as other factors that determine their perception, to evaluate consumers' mean WTP for safety and quality attributes of chicken and to identify the determinants of WTP for these attributes. Existing (or intrinsic) attributes refer to the physical aspects of the product, which cannot be modified without modifying the characteristics of the product itself. These include cleanness or appearance, colour, leanness, natural shape among others. Innovative (or extrinsic) attributes, on the other hand, are introduced by a marketer or retailer to enhance its appeal and value. They can be 
modified without modifying the physical product. Such attributes include brand, origin or traceability to place of origin, sales outlet type, transparency and certification. These attributes can also be divided into existing and innovative attributes depending on the area of study and their prior existence or otherwise in such areas.

\section{Materials and Methods}

\section{Study area}

The study was carried out in Ibadan, the capital city of Oyo State, Nigeria. Ibadan is made up of eleven local governments, is the largest indigenous city in West Africa and is located in the South-Western part of Oyo state, a distance of about 145 kilometres north east of Lagos. The approximate coordinates of the city are $7^{0} 23^{\prime} 47^{\prime \prime} \mathrm{N} 3^{0} 55^{\prime} 0^{\prime \prime} \mathrm{E}$

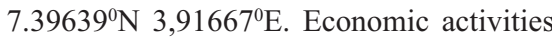
undertaken by people in Ibadan include trading, public service, and agriculture in decreasing order of importance. Ibadan has a population of 2,550,593 people (National Population Census, 2006) and the principal inhabitants of the city were the Yoruba people. In Ibadan metropolis, chicken is the second largest consumed animal product after beef (FAO, 2010).

\section{Data and sampling methodology}

Primary data for the study was collected using a structured questionnaire. Further, a multi-stage sampling technique was used to elicit information from the respondents as follows: first, a stratification of the 12 wards in Ibadan North Local Government Area (LGA) based on their household densities was adopted. Next, a total of four wards were selected from the three strata. One ward was selected randomly from each of the high and low density areas while two were randomly selected from the medium density area since more wards belonged to this category.

Finally, actual respondents were selected randomly from each of the wards on a proportionate-to-size basis, making a total of 120 households used for the study.

\section{Analytical techniques}

Both descriptive analytics and an exploratory approach were used in this study. The descriptive instruments employed included tables, frequency distributions, graphs, measures of central tendency, percentages, standard deviations, among others, which were used to describe and summarise information on respondents' demographics while their risk attitudes and perception of safety attributes of chicken was measured using a five-point Likert scale. Likert scaling is a bipolar scaling method, measuring either positive or negative responses to a statement. It is an ordinal psychometric measurement of attitudes, beliefs and opinions. A statement is presented in which a respondent must indicate a degree of agreement or disagreement to a series of questions in a multiple-choice type format. The method is easily understood, easy to code, and responses are easily quantifiable and can be subjected to mathematical computation and analysis (LaMarca, 2011). The perception responses were obtained from qualitative focus group investigations and expert meetings with chicken industry players while risk attitude statements were adopted from Bard and Barry (2000). The food safety statements were worded such that they did not always imply the same direction of agreement. Some statements were altered from the original survey in order for their responses to imply the same direction of agreement with the underlying construct with response choices ranging from strongly disagree to strongly agree on a numeric scale of 1 to 5 .

Based on the work of Bard and Barry (2000), consumers were categorized into three risk groups by adding the mean of their responses to the standard deviation to obtain an upper limit of 50.57 while subtracting the standard deviation from the mean to get a lower limit of 35.39. Therefore, a consumer was considered to be risk averse if they obtained a score $(\mathrm{X}) \leq$ 35.39 , risk loving if they obtained a score $(\mathrm{X}) \geq 50.57$ and risk neutral if they obtained a score $(X)$ between 50.57 and 35.39 (that is $35.39 \leq \mathrm{X} \leq 50.57)$.

The other analytical tools used are discussed as follows. First, a binary logit regression model was used to generate the coefficients used to compute the Mean Willingness to Pay (MWTP) for the attributes as follows: first, responses on WTP four potential price levels of 1,000 Naira, 1,200 Naira, 1,400 Naira and 1,500 Naira per kilogramme of safe chicken were sought from consumers. These were as against the current market price of 850 Naira per kilogramme (as at the time of carrying out this study). The price levels chosen were conditional prices set to reflect the value placed by consumers on groups of improved food safety attributes of chicken meat by eliciting responses on whether they would be willing to pay those prices to enjoy those attributes. Each new price level was gotten from the adjustment of the previous price to reflect what the proposed improvement would cost based on information from retailers. The price ranges were such that at the low end anyone who valued improved chicken products with safety and innovative attributes would be likely to pay at least 1,000 Naira, whereas no one was expected to pay more than 1,500 Naira per kilogram.

The attributes and the conditional prices of chicken meat having those attributes are as follows: i) Cleanness and Leanness = 1,000 Naira; ii) Cleanness and Leanness + Safety Assurance (certification) and Frozen = 1,200 Naira; iii) Cleanness and Leanness + Safety Assurance (certification) and Frozen + Transparency and Traceability $=$ 1,400 Naira; iv) Cleanness and Leanness + Safety Assurance (certification) and Frozen + Transparency and Traceability + Labelling, Packaging, Sales Outlet Type and Organic $=1,500$ Naira.

Next, the responses to the WTP question were regressed on the price levels specified as shown in the multinomial logit model in equation 1. Finally, the coefficient estimates obtained were used to calculate the MWTP using equation 2.

$$
Y=\frac{1}{1+\exp \left(\beta_{0}+\beta_{1} P_{i}\right)}
$$

$$
\text { Mean } \mathrm{WTP}=\frac{1}{\beta_{1}{ }^{\circ}} \ln \left(1+\exp \beta_{0}\right)
$$

where:

$Y=$ response to the WTP question ( $\mathrm{Y}=1$ if yes, 0 otherwise)

$\beta 0=$ constant term

$\beta 1=$ coefficient of the price level variable specified for chicken with improved attributes

$P_{i}=$ the different price levels specified for chicken with improved attributes

$W T P=$ WTP for the safe chicken

Secondly, to obtain the determinants of WTP, the responses to the WTP question were regressed on the price levels as well as other socio-economic characteristics of the respondents. Following Hanemann (1989) and Whittington et al. (1990) the model is thus specified:

$$
Y=\frac{1}{1+\exp \left(\beta_{0}+\beta_{i} X_{i}\right)}
$$

where:

$Y=$ Response to the WTP question ( $\mathrm{Y}=1$ if yes, 0 otherwise)

$\beta 0=$ Constant term

$\beta 1=$ Coefficients of explanatory variables

$\mathrm{X}_{1} \ldots \mathrm{X}_{12}$

$\mathrm{X}_{1}=$ Age of consumers in years

$\mathrm{X}_{2}=$ Sex of respondents ( 1 if male, 0 otherwise)

$\mathrm{X}_{3}=$ Marital status of consumers ( 1 if married and 0 otherwise) 
$\mathrm{X}_{4}=$ Years of formal education (Years)

$\mathrm{X}_{5}=$ Household size of consumers (Number)

$\mathrm{X}_{6}=$ Health imbalance experienced (1 if yes, 0 if otherwise)

$\mathrm{X}_{7}=$ Grocery Shopping for the household (1 if yes, 0 if otherwise)

$\mathrm{X}_{8}=$ Ever fallen sick as a result of unsafe chicken consumption ( 1 if yes, 0 if otherwise)

$\mathrm{X}_{9}=$ WTP prices

$\mathrm{X}_{10}=$ Monthly income of consumers in Naira

$\mathrm{X}_{11}=$ Risk averseness

$\mathrm{X}_{12}=$ Risk neutrality

The AGE $\left(\mathrm{X}_{1}\right)$ of the consumer was measured in number of completed years. MARITAL STATUS $\left(\mathrm{X}_{3}\right)$ was restricted to two categories: married, representing all consumers who lived under the same roofs as their partners either in formal or informal unions, and single, representing respondents who were never married, widowed, separated or divorced. YEARS OF FORMAL EDUCATION $\left(\mathrm{X}_{4}\right)$ was conceptualized as the number of completed years a respondent had spent acquiring formal education from the basic to the tertiary levels. HOUSEHOLD SIZE $\left(\mathrm{X}_{5}\right)$, on the other hand, referred to the number of persons who lived under the same roof with the respondent including all dependants. A respondent was categorized as having experienced a HEALTH IMBALANCE $\left(\mathrm{X}_{6}\right)$ if they had a previous or ongoing chronic health challenge. MONTLY INCOME $\left(\mathrm{X}_{10}\right)$ was captured as the income received by consumers from their primary occupations on a monthly basis. RISK NEUTRALITY $\left(\mathrm{X}_{11}\right)$ and RISK AVERSENESS $\left(\mathrm{X}_{12}\right)$ were computed as explained earlier in the section.

\section{Results and discussion}

\section{Socioeconomics characteristics of consumers}

Majority of the respondents $(64.1 \%)$ were 40 years of age or younger. Moreover, the average age of the respondents was 38 years showing that most of the persons interviewed were still within their economically active years. Married respondents constituted $72.5 \%$ of the sample, while about $83.3 \%$ of consumers were educated up to tertiary level with 13 years and above of formal education. This might have been as a result of the presence of two tertiary institutions in the study area. Hence, it is expected that consumers in the study area would be more health and food safety conscious with a considerable level of exposure to food safety and quality information. Over half $(69 \%)$ of the respondents have a household size of between 4-6 members with the mean household size of 5 members which is a bit above the average household size of 4 members in the country according to Adeyonu et al. (2016).

Civil servants made up $48.3 \%$ of respondents and this might be due to the fact that the area is urban with so many government parastatals and institutions. Traders made up $23.3 \%$ of respondents, $5.8 \%$ were artisans, 5\% were agriculturists and $17.5 \%$ came under the category of others including students, professionals among others. With such a distribution of occupations, it is expected that many in the study area would have a good knowledge of the health impli-

Table 1. Summary information on household income and chicken consumption.

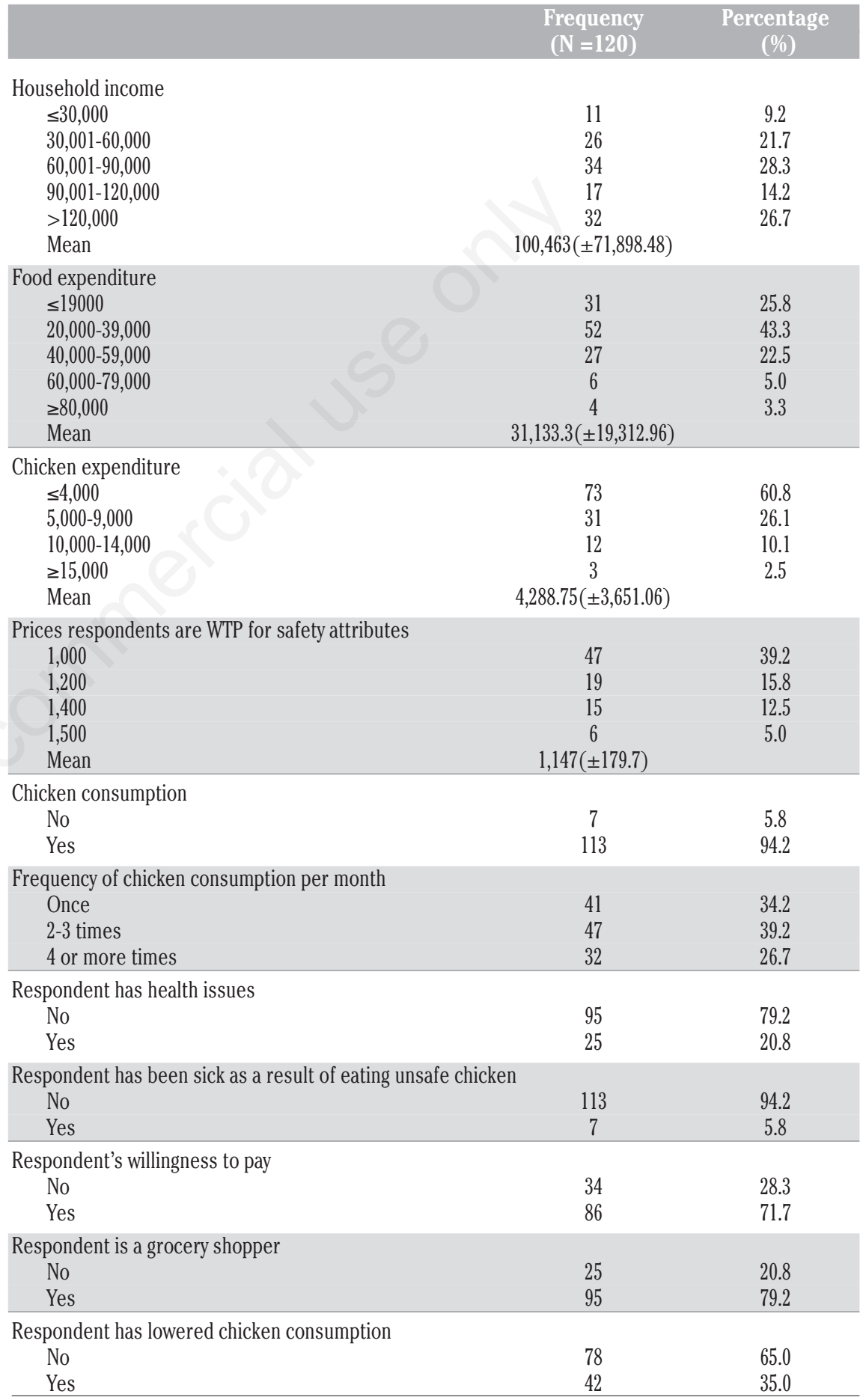

Note: Standard deviations are presented in parenthesis. 
cations of consuming unsafe chicken and might be more aware of the safety and innovative attributes to look out for when purchasing chicken.

\section{Analysis of household consumption of chicken}

Table 1 shows that the majority of respondents sampled (94\%) consume chicken and $39.2 \%$ of them consume chicken 2 to 3 times a month indicating a relatively high chicken consumption in the study area. Almost $79.2 \%$ of the consumers were grocery shoppers (that is, they shop for $50 \%$ of household groceries) and $65 \%$ of them were females. This is attributable to the fact that in most households in Nigeria, females are responsible for purchasing and preparing of food.

Around $94 \%$ of the consumers had never been sick as a result of consuming chicken while $79.2 \%$ did not have health issues that required that they watch what they eat, thus explaining why $65 \%$ of consumers never lowered their chicken con- sumption over the years. These results could imply that consumers of chicken in Ibadan North local government were healthy and the level of safety of the chicken sold in this area was high. It could also imply that household consumers of chicken in this area were less concerned about the negative health effects that could arise from the consumption of unsafe chicken. Also, $71.7 \%$ of respondents were willing to pay for improved and safer chicken, this high percentage could be as a result of the high concentration of educated chicken consumers from middle to high-income households who know the implication of eating unsafe chicken and can afford to pay a premium for safer chicken.

Only $35 \%$ of respondents have lowered chicken consumption due to safety concerns and going by Table 2, $51.7 \%$ of respondents claim to be satisfied with the level of safety and quality of chicken meat sold in Nigerian markets today. Therefore, it can be said that consumers are moderately con- vinced of the safety and quality of chicken sold in their markets.

\section{Analysis of households' monthly food expenditure}

Table 1 shows that the monthly food expenditure of majority of the households (43\%) was between 20,000 and 39,000 Naira, with a mean food expenditure of 31,333.30 Naira while the chicken expenditure of $60.8 \%$ of respondents was 4,000 Naira or less with a mean chicken expenditure of 4,288.75 Naira. This implies that on the average, only one-seventh of households' total food expenditure was spent on the purchase of chicken. Hence, chicken meat constitutes a considerably low fraction of the total food expenditure of Ibadan residents. This could imply that respondents have reservations about purchasing chicken as a substitute for other protein sources, either because of safety and quality concerns, the presence of cheaper alternatives or due to preference.

Table 2. Perception of safety and innovative attributes of chicken. Figures in parenthesis are percentages

\begin{tabular}{|c|c|c|c|c|c|c|c|c|}
\hline $\begin{array}{l}\text { Perception } \\
\text { statement }\end{array}$ & SD & $\begin{array}{c}\text { D } \\
(1)\end{array}$ & $\begin{array}{l}\text { UD } \\
(2)\end{array}$ & $\begin{array}{c}\text { A } \\
(3)\end{array}$ & $\begin{array}{l}\text { SA } \\
(4)\end{array}$ & $\begin{array}{l}\text { Weighted } \\
\text { (5) }\end{array}$ & $\begin{array}{l}\text { Average } \\
\text { score }\end{array}$ & $\begin{array}{l}\text { Rank } \\
\text { score }\end{array}$ \\
\hline 1 Satisfied with the level of safety and quality of chicken & $\begin{array}{c}14 \\
(11.7)\end{array}$ & $\begin{array}{c}26 \\
(21.7)\end{array}$ & $\begin{array}{c}18 \\
(15.0)\end{array}$ & $\begin{array}{c}45 \\
(37.5)\end{array}$ & $\begin{array}{c}17 \\
(14.2)\end{array}$ & 385 & 3.21 & $12 \mathrm{TH}$ \\
\hline 2 Certification assures safety and quality & $\begin{array}{c}7 \\
(5.8)\end{array}$ & $\begin{array}{c}14 \\
(11.7)\end{array}$ & $\begin{array}{c}12 \\
(10.0)\end{array}$ & $\begin{array}{c}54 \\
(45.0)\end{array}$ & $\begin{array}{c}33 \\
(27.5)\end{array}$ & 452 & 3.77 & $5 \mathrm{TH}$ \\
\hline 3 Naturally grown chicken assures safety and quality & $\begin{array}{c}1 \\
(0.8)\end{array}$ & $\begin{array}{c}3 \\
(2.5)\end{array}$ & $\begin{array}{c}5 \\
(4.2)\end{array}$ & $\begin{array}{c}49 \\
(40.8)\end{array}$ & $\begin{array}{c}62 \\
(51.7)\end{array}$ & 528 & 4.40 & 1ST \\
\hline 4 Cleanness assures chicken safety and quality & $\begin{array}{c}1 \\
(0.8)\end{array}$ & $\begin{array}{c}5 \\
(4.2)\end{array}$ & $\begin{array}{c}4 \\
(3.3)\end{array}$ & $\begin{array}{c}54 \\
(45.0)\end{array}$ & $\begin{array}{c}56 \\
(46.7)\end{array}$ & 519 & 4.33 & 2ND \\
\hline 5 Transparency assures the safety and quality of chicken & & $\begin{array}{c}10 \\
(8.3)\end{array}$ & $\begin{array}{c}12 \\
(10.0)\end{array}$ & $\begin{array}{c}60 \\
(50.0)\end{array}$ & $\begin{array}{c}38 \\
(31.7)\end{array}$ & 486 & 4.05 & $3 R D$ \\
\hline 6 Traceability assures the safety and quality of chicken & $\begin{array}{c}10 \\
(8.3)\end{array}$ & $\begin{array}{c}12 \\
(10.0)\end{array}$ & $\begin{array}{c}24 \\
(20.0)\end{array}$ & $\begin{array}{c}44 \\
(36.7)\end{array}$ & $\begin{array}{c}30 \\
(25.0)\end{array}$ & 432 & 3.60 & 7TH \\
\hline 7 Antibiotic and chemical-free chicken is safer than chicken treated with both & $\begin{array}{c}6 \\
(5.0)\end{array}$ & $\begin{array}{c}9 \\
(7.5)\end{array}$ & $\begin{array}{c}21 \\
(17.5)\end{array}$ & $\begin{array}{c}41 \\
(34.2)\end{array}$ & $\begin{array}{c}43 \\
(35.8)\end{array}$ & 466 & 3.88 & $4 \mathrm{TH}$ \\
\hline 8 Safety tags(best before, chemical free tags assures safety and quality & $\begin{array}{c}5 \\
(4.2)\end{array}$ & $\begin{array}{c}20 \\
(16.7)\end{array}$ & $\begin{array}{c}18 \\
(15.0)\end{array}$ & $\begin{array}{c}47 \\
(39.2)\end{array}$ & $\begin{array}{c}30 \\
(25.0)\end{array}$ & 437 & 3.64 & $6 \mathrm{TH}$ \\
\hline $\begin{array}{l}9 \text { Labelling of chicken products ( brand nutritional and handling information) } \\
\text { assures its safety and quality }\end{array}$ & $\begin{array}{c}8 \\
(6.7)\end{array}$ & $\begin{array}{c}21 \\
(17.5)\end{array}$ & $\begin{array}{c}21 \\
(17.5)\end{array}$ & $\begin{array}{c}46 \\
(38.3)\end{array}$ & $\begin{array}{c}24 \\
(20.0)\end{array}$ & 417 & 3.48 & 8TH \\
\hline 10 Packaging assures the safety and quality of chicken & $\begin{array}{c}5 \\
(4.2)\end{array}$ & $\begin{array}{c}30 \\
(25.0)\end{array}$ & $\begin{array}{c}19 \\
(15.8)\end{array}$ & $\begin{array}{c}38 \\
(31.7)\end{array}$ & $\begin{array}{c}28 \\
(23.3)\end{array}$ & 414 & 3.45 & 9TH \\
\hline 11 Frozen chicken is safe and of high quality & $\begin{array}{c}11 \\
(9.2)\end{array}$ & $\begin{array}{c}38 \\
(31.7)\end{array}$ & $\begin{array}{c}26 \\
(21.7)\end{array}$ & $\begin{array}{c}30 \\
(25.0)\end{array}$ & $\begin{array}{c}15 \\
(12.5)\end{array}$ & 360 & 3.00 & 13TH \\
\hline 12 The fat content of chicken meat says a lot about its safety and quality. & $\begin{array}{c}4 \\
(3.3)\end{array}$ & $\begin{array}{c}29 \\
(24.2)\end{array}$ & $\begin{array}{c}32 \\
(26.7)\end{array}$ & $\begin{array}{c}37 \\
(30.8)\end{array}$ & $\begin{array}{c}18 \\
(15.0)\end{array}$ & 396 & 3.30 & $11 \mathrm{TH}$ \\
\hline 13 Chicken sales outlet assures or determines the safety and quality of chicken meat & $\begin{array}{c}4 \\
(3.3)\end{array}$ & $\begin{array}{c}22 \\
(18.3)\end{array}$ & $\begin{array}{c}27 \\
(22.5)\end{array}$ & $\begin{array}{c}50 \\
(41.7)\end{array}$ & $\begin{array}{c}17 \\
(14.2)\end{array}$ & 414 & 3.45 & $10 \mathrm{TH}$ \\
\hline 14 Online chicken is safe & $\begin{array}{c}30 \\
(25.0)\end{array}$ & $\begin{array}{c}38 \\
(31.7)\end{array}$ & $\begin{array}{c}28 \\
(23.3)\end{array}$ & $\begin{array}{c}15 \\
(12.5)\end{array}$ & $\begin{array}{c}9 \\
(7.5)\end{array}$ & 295 & 2.46 & $16 \mathrm{TH}$ \\
\hline 150nline chicken might meet quality expectations & $\begin{array}{c}21 \\
(17.5)\end{array}$ & $\begin{array}{c}38 \\
(31.7)\end{array}$ & $\begin{array}{c}37 \\
(30.8)\end{array}$ & $\begin{array}{c}12 \\
(10.0)\end{array}$ & $\begin{array}{c}12 \\
(10.0)\end{array}$ & 316 & 2.63 & $15 \mathrm{TH}$ \\
\hline $\begin{array}{l}16 \text { Improving the safety and quality of chicken meat will not give more } \\
\text { than the usual satisfaction. }\end{array}$ & $\begin{array}{c}22 \\
(18.3)\end{array}$ & $\begin{array}{c}31 \\
(25.8)\end{array}$ & $\begin{array}{c}15 \\
(12.5)\end{array}$ & $\begin{array}{c}32 \\
(26.7)\end{array}$ & $\begin{array}{c}20 \\
(16.7)\end{array}$ & 357 & 2.98 & $14 \mathrm{TH}$ \\
\hline
\end{tabular}




\section{Analysis of the importance of safety and innovative attributes to con- sumers}

In ranking the safety and innovative attributes in Table 3, the identified attributes of chicken products were rated in order of the importance consumers attached to them using the weighted average score and mean ranks.

The consumers of chicken in Ibadan north local government ranked Cleanness, Certification, Organic product, Transparency and Traceability, Packaging, Sale outlet type, Leanness, Labeling, and Frozen product as the $1^{\text {st }}, 2^{\text {nd }}, 3^{\text {rd }}, 4^{\text {th }}, 5^{\text {th }}, 6^{\text {th }}$, $7^{\text {th }}, 8^{\text {th }}$, and $9^{\text {th }}$ respectively in order of how important these attributes are in determining their purchasing decision for safe and quality chicken.

These results were consistent with that of Annan-Prah et al. (2012). The ratings may be attributed to the fact that most of the respondents were educated and thus knew the importance of hygiene and certification of chicken products by a regulatory body when it comes to the purchase of safe and quality chicken. They were also aware of the hazards of consuming too much of processed or frozen chicken, hence their choice for Organic chicken over frozen processed chicken. They viewed Leanness (low fat content), Labelling, Sale outlet type, and Packaging as some of their least important attributes for the choice of a safe and quality chicken product because most conventional chicken products sold in Ibadan metropolis are not packaged or well labelled in most retail stores available.

Traceability and transparency, labelling and online market were regarded as not so important because consumers of chicken in the area were least aware of these attributes. They also could not trace the origin of chicken products they consumed as they were mostly not labelled and only a few companies sold their products online. The results, therefore, imply that innovative attributes are less important in determining consumers purchasing decision for safe and quality chicken.

\section{Consumers' perception of safety and innovative attributes of chicken}

Sixteen perception questions were asked the consumers to determine their perception of safety and innovative attributes of chicken. According to the results in Table 2 , household consumers of chicken strongly believed that naturally grown chicken, cleanness, and transparency about the presence of antibiotics and chemicals are important criteria for assuring chicken safety and quality, while they believed that online sale of chicken, frozen chicken, low fat content (leanness), sale outlet types, packaging of chicken and labelling would give a lesser assurance of the safety and quality of chicken. This result is consistent with that of Yusuf (2011). Packaging, labelling, online sale outlets are not supported by consumers to be a valid criterion for safe and quality chicken because they are considered as unnecessary and costly by $43.1 \%$ of respon- dents and, as such, would eventually increase the product price. These facts imply that consumers are more concerned about the existence of safety attributes than innovative attributes such as the aforementioned. This could also be due to the risk neutral attitude of respondents to innovative attributes and food safety issues, the fact that respondents (consumers) were satisfied with the already existing levels of chicken safety and the fact that the purchase of chicken with new attributes or attributes which are close to non-existent in the market do not necessarily translate to assurance of the safety of chicken. Most of the innovative attributes such as online retail outlet, labelling, packaging, and traceability were considered to be of least importance in assuring consumers of the safety and quality of chicken except for certification and transparency with occupied the $5^{\text {th }}$ and $3^{\text {rd }}$ ranks respectively. Since awareness has an effect on preference and perception, this could be due to the lack of awareness about these attributes and their advantages. Already existing attributes such as Cleanness and Organic chicken were ranked higher in assuring consumers of the safety and quality of chicken except fat content and frozen attributes, which were the least preferred.

Naturally grown chicken meat was the most preferred attribute in terms of assuring respondents of the safety and quality of chicken meat while freezing $\left(13^{\text {th }}\right)$ is one of the least most preferred. Hence organically grown chicken assures respondents of the

Table 3. Ranking of safety and innovative attributes by consumers.

\begin{tabular}{|c|c|c|c|c|c|c|c|c|c|}
\hline & Product attributes & $\begin{array}{c}\text { Very } \\
\text { Important }\end{array}$ & Important & $\begin{array}{c}\text { Fairly } \\
\text { Important }\end{array}$ & $\begin{array}{l}\text { Not very } \\
\text { Important }\end{array}$ & $\begin{array}{c}\text { Not } \\
\text { Important }\end{array}$ & Sum & Weight & Rank \\
\hline $\mathrm{A}$ & Cleanness & $\begin{array}{c}103 \\
(85.8)\end{array}$ & $\begin{array}{c}12 \\
(10.0)\end{array}$ & $\begin{array}{c}2 \\
(1.7)\end{array}$ & $\begin{array}{c}1 \\
(0.8)\end{array}$ & $\begin{array}{c}2 \\
(1.7)\end{array}$ & 573 & 4.775 & 1ST \\
\hline B & Leanness (Low Fat Content) & $\begin{array}{c}44 \\
(36.7)\end{array}$ & $\begin{array}{c}41 \\
(34.2)\end{array}$ & $\begin{array}{c}9 \\
(7.5)\end{array}$ & $\begin{array}{c}15 \\
(12.5) \\
\end{array}$ & $\begin{array}{c}11 \\
(9.2)\end{array}$ & 452 & 3.767 & $7 \mathrm{TH}$ \\
\hline $\mathrm{C}$ & Safety Assurance (Certification) & $\begin{array}{c}72 \\
(60.0)\end{array}$ & $\begin{array}{c}27 \\
(22.5)\end{array}$ & $\begin{array}{c}11 \\
(9.2)\end{array}$ & $\begin{array}{c}7 \\
(5.8)\end{array}$ & $\begin{array}{c}3 \\
(2.5)\end{array}$ & 518 & 4.317 & $2 \mathrm{ND}$ \\
\hline D & Frozen & $\begin{array}{c}26 \\
(21.7)\end{array}$ & $\begin{array}{c}32 \\
(26.7)\end{array}$ & $\begin{array}{c}18 \\
(15.0)\end{array}$ & $\begin{array}{c}20 \\
(16.7)\end{array}$ & $\begin{array}{c}24 \\
(20.0)\end{array}$ & 376 & 3.133 & 9TH \\
\hline E & Transparency and Traceability & $\begin{array}{c}49 \\
(40.8)\end{array}$ & $\begin{array}{c}29 \\
(24.2)\end{array}$ & $\begin{array}{c}26 \\
(21.7)\end{array}$ & $\begin{array}{c}10 \\
(8.3)\end{array}$ & $\begin{array}{c}6 \\
(5.0)\end{array}$ & 465 & 3.875 & $4 \mathrm{TH}$ \\
\hline $\mathrm{F}$ & Labelling & $\begin{array}{c}42 \\
(35.0)\end{array}$ & $\begin{array}{c}29 \\
(24.2)\end{array}$ & $\begin{array}{c}19 \\
(15.8)\end{array}$ & $\begin{array}{c}19 \\
(15.8)\end{array}$ & $\begin{array}{c}11 \\
(9.2)\end{array}$ & 432 & 3.600 & 8TH \\
\hline G & Packaging & $\begin{array}{c}44 \\
(36.7)\end{array}$ & $\begin{array}{c}35 \\
(29.2)\end{array}$ & $\begin{array}{c}21 \\
(17.5)\end{array}$ & $\begin{array}{c}18 \\
(15.0)\end{array}$ & $\begin{array}{c}2 \\
(1.7)\end{array}$ & 461 & 3.842 & $5 \mathrm{TH}$ \\
\hline $\mathrm{H}$ & Sales Outlet Type & $\begin{array}{c}49 \\
(40.8)\end{array}$ & $\begin{array}{c}25 \\
(20.8)\end{array}$ & $\begin{array}{c}27 \\
(22.5)\end{array}$ & $\begin{array}{c}15 \\
(12.5)\end{array}$ & $\begin{array}{c}4 \\
(3.3)\end{array}$ & 460 & 3.833 & $6 \mathrm{TH}$ \\
\hline $\mathrm{I}$ & Organic & $\begin{array}{c}73 \\
(60.8)\end{array}$ & $\begin{array}{c}21 \\
(17.5)\end{array}$ & $\begin{array}{c}12 \\
(10.0)\end{array}$ & $\begin{array}{c}8 \\
(6.7) \\
\end{array}$ & $\begin{array}{c}6 \\
(5.0) \\
\end{array}$ & 507 & 4.225 & 3RD \\
\hline
\end{tabular}


safety and quality of chicken over frozen chicken and local producers could focus on filling this gap in the market. Only $33.4 \%$ of respondents were not satisfied with the level of safety and quality of chicken sold in markets. Although $43.4 \%$ of the respondents felt that increasing the safety and quality of these attributes only increases the cost and do not give more than the usual satisfaction, $44.1 \%$ felt otherwise. This implies that a number of consumers were interested in the improvement of chicken safety attributes. These indicators are useful for producers seeking to fill consumers' needs.

\section{Risk attitude of consumers of chicken}

Risk attitude is the chosen response of an individual or group to uncertainty, driven by their perception. Table 4 presents statistics for risk attitude statements, which were adopted from Bard and Barry (2000). The statements were worded such that they did not always imply the same direction of the agreement. The statements were negatively worded, and the response choices ranged from strongly agree to strongly disagree with a numeric scale of 1 to 5 , respectively; where 1 meant strongly disagree, 3 indicated neither disagree nor agree and 5 indicated that respondents strongly agreed with the statement.

Based on their responses to the ques- tions in Table 4, the lowest score a respondent could attain was 14 while the highest score was 70. Following Fatuase and Ajibefun (2014), consumers were categorised into into risk averse, risk neutral, and risk loving. This was done by adding the mean to the standard deviation (SD) of the response scores to generate an upper limit (50.57) while subtracting the SD from the mean to derive a lower (35.39). Respondents with mean scores $\leq 35.39$ were considered to be risk averse, while those with mean scores $\geq 50.57$ were risk loving and risk neutral persons were reckoned to be those with mean scores between 50.57 and 35.39 , excluding those limits (that is $35.39<$ Risk Neutral $<50.57$ ).

The results reveal that $73.3 \%$ of the consumers were risk-neutral. The percentage of risk loving respondents was the lowest $(12.5 \%)$. This might have an influence on the perception and WTP for innovative attributes of chicken meat as it is expected that the higher the proportion of risk lovers, the higher their WTP for new attributes. Therefore, it is not surprising that consumers are indifferent to improvements in chicken safety attributes. The high percentage of risk neutral individuals in the study corresponded to the high percentage of individuals with a moderate perception for safety and innovative attributes of chicken.

\section{Determinants of consumers' WTP for safety and innovative attributes of chicken}

Table 5 shows the determinants of consumers' WTP for safety and innovative attributes of chicken in Ibadan. WTP refers to the desire (or otherwise) of a consumer to pay a premium in order to enjoy specific quality attributes of chicken. The model used was a good fit for the data with the Chi-square value of the regression being statistically significant at $1 \%(\mathrm{P}>0.0025)$, while the Pseudo $\mathrm{R}^{2}$ indicates that about $30.5 \%$ of the variations in the dependent variable (WTP) were explained by the independent variables. Seven of the variables were significant at various levels of significance.

Age was significant at $10 \%$ and was positively related to WTP for safety and innovative attributes of chicken. This shows that WTP increases as age increases. Essentially, this implies that older consumers are more likely to pay a premium for safer chicken because of their health consciousness. This result is consistent with that of Ehirim (2010) who inferred that as age increases, consumer's preference for safer chicken also increases. Sex was significant at $1 \%$ and negatively related to WTP. This indicated that men were less likely to pay for safety and innovative attributes of

Table 4. Risk attitude analysis of consumers.

\begin{tabular}{|c|c|c|c|c|c|c|c|}
\hline & Statement & Mean & Median & Mode & SD & $\operatorname{Max}$ & Min \\
\hline 1 & I have never paid for any insurance before (e.g. car insurance, life insurance) & 3.10 & 3 & 4 & 1.350 & 5 & 1 \\
\hline 2 & I remain calm in situations where most people become fearful and stressed. & 3.39 & 4 & 4 & 1.169 & 5 & 1 \\
\hline 3 & I follow the motto no risk no gain & 2.90 & 3 & 1 & 1.563 & 5 & 1 \\
\hline 4 & I am indifferent to new technologies and new foods & 2.57 & 2 & 2 & 1.333 & 5 & 1 \\
\hline 5 & I am always the first in my click of friends and family to adopt new things & 3.56 & 4 & 4 & 1.222 & 5 & 1 \\
\hline 6 & I rarely think about the safety of chicken when eating it & 3.87 & 4 & 4 & 1.144 & 5 & 1 \\
\hline 7 & I would take a risk even if I am not aware of its benefits & 4.11 & 4 & 4 & 1.035 & 5 & 1 \\
\hline 8 & I have only one or two streams of income & 2.48 & 2 & 2 & 1.237 & 5 & 1 \\
\hline 9 & I always save in case of emergency (Reversed) & 3.27 & 3 & 4 & 1.221 & 5 & 1 \\
\hline 10 & I prefer to buy products I am more familiar with (Reversed) & 2.88 & 3 & 2 & 1.278 & 5 & 1 \\
\hline 11 & I do not look for guarantees in risky purchases & 2.35 & 2 & 1 & 1.333 & 5 & 1 \\
\hline 12 & I feel nervous when I have to make decisions in uncertain situations.(Reversed) & 3.27 & 3 & 4 & 1.221 & 5 & 1 \\
\hline 13 & I am not afraid to eat foods I have never had before. & 2.88 & 3 & 2 & 1.278 & 5 & 1 \\
\hline 14 & Not bothered about the health implications that may arise as a result of consuming new food. & 2.35 & 2 & 1 & 1.333 & 5 & 1 \\
\hline 15 & Risk Attitude Categories (scores ranges) & & \multicolumn{5}{|c|}{ Frequency $(\mathrm{N}=120) \quad$ Percentage } \\
\hline 16 & Risk averse (14-33) & & \multicolumn{3}{|c|}{17} & \multicolumn{2}{|c|}{14.2} \\
\hline 17 & Risk neutral (34-51) & & \multicolumn{3}{|c|}{88} & \multicolumn{2}{|l|}{73.3} \\
\hline 18 & Risk loving (52-70) & & \multicolumn{3}{|c|}{15} & \multicolumn{2}{|l|}{12.5} \\
\hline 19 & Mean & \multicolumn{6}{|c|}{42.98} \\
\hline 20 & Standard deviation & \multicolumn{6}{|c|}{7.59} \\
\hline 21 & Minimum & \multicolumn{6}{|c|}{14} \\
\hline
\end{tabular}


chicken than women. This is logical, as women tend to be in charge of the nutrition and health of their families and would naturally be more concerned about health and food safety issues. Household size had a negative relationship with WTP, significant at $1 \%$. This implies that as household size increases WTP decreases. As household size increases, the dependency ratio increases while per capita income reduces. This could affect the willingness of such households to pay a premium for safer chicken as a result of leaner resources.

There was a negative relationship between being a grocery shopper and WTP, significant at $1 \%$. This implies that a person who is the household grocery shopper (shops for more than $50 \%$ of household groceries) is more familiar with the prices of substitutes to chicken (such as goat meat, turkey, beef among others). Hence an increase in the price of chicken brings about an increase in his/her demand for substitute goods and a decrease in grocery shopper's WTP a premium for improved chicken.

The price levels were inversely related to WTP. This meant that as the prices of safer chicken increased, the demand for the commodity decreased showing that chicken is a normal good in Ibadan. Income was positively significant at 5\% indicating that an increase in income would increase WTP of the household as they would then be able to afford the extra premium for safer chicken.

Using Haenemann's model (1989), the mean WTP was calculated as follows: Mean

$$
\mathrm{WTP}=\frac{1}{\beta_{1}{ }^{*}} \ln \left(1+\exp \beta_{0}\right)
$$

where:

$$
\beta 1=\text { pricecoefficent }
$$

$\beta 0=$ constant

Therefore, the Mean WTP = $1 / 0.0002588 *$ LOG $\left(1+\exp ^{0.4745758}\right)$.

That is; $0.958327561 / 0.000258=1$, 613.16 Naira.

The mean WTP for safety and innovative attributes of chicken in Ibadan metropolis, of Nigeria, was calculated to be 1, 613.16 Naira. Thus, consumers of chicken in the study area will pay as much as 1 , 613.16 Naira for chicken that guarantees them the desirable safety and innovative attributes.

\section{Conclusions and \\ Recommendations}

Consumers of chicken and chicken products in Ibadan metropolis are moderately aware of existing innovative and safety attributes but have a stronger perception and preference for existing attributes over innovative attributes in assuring them of the safety and quality of chicken. Most consumers are minimally concerned about the safety of chicken consumed because of their risk neutral disposition. Also, an increase in the price of safer chicken tends to override the effect of the perception of consumers of these attributes. Gender, household size, major occupation, being a grocery shopper,
WTP prices, income and age all significantly influence the WTP a premium for safety and innovative attributes of chicken by consumers. The positive mean WTP estimate obtained implies that households will be willing to pay an average of 1,613.14 Naira if the proposed safety and innovative attributes of chicken will improve chicken safety and give more than the usual satisfaction derived from its consumption.

Based on the foregoing, the following recommendations were made: i) The level of awareness about innovative safety attributes of chicken is low, and since awareness affects WTP for improved and safer chicken, there is a need for the sensitization of consumers and retailers about chicken and general food safety in the area; ii) Key players in the value chain should focus on attributes which are of importance to consumers in assuring them of the safety and quality of chicken as these attributes contribute to their purchasing decision. They should design their marketing strategies in line with these attributes; iii) The Nigerian chicken industry could use selective demographic targeting to maintain and build their market share among competing chicken brands from exporting countries based on the findings of this study that reveal the specific demographics that would be willing to pay for improved or safer chicken produced domestically; iv) An enabling business environment that allows for the minimal cost of adopting these innovative and safety attributes in chicken production and marketing should be fostered in other to keep prices at a minimum, increase retailers' profit as well as consumers' satisfaction in consuming safer chicken.

Table 5. Parameter estimates of the determinants of consumers' willingness to pay for safety and innovative attributes of chicken.

\begin{tabular}{lccccc} 
Variables & Coefficient & Standard Brror & Marginal Effects & Z value & P $>[\mathbf{z}]$ value \\
Age & 0.0443969 & 0.0248079 & 0.0095135 & 1.79 & 0.074 \\
Sex & -1.329136 & 0.4673431 & -0.2289377 & -2.84 & 0.004 \\
\hline Marital status & -0.1895709 & 0.5633731 & -0.0412471 & -0.34 & 0.736 \\
Years of education & -0.1092091 & 0.1032778 & -0.0234017 & -1.06 & 0.290 \\
\hline Household size & -0.4353774 & 0.166366 & -0.0932943 & -2.62 & 0.009 \\
Health imbalance & 0.7827738 & 0.523955 & 0.1790041 & 1.49 & 0.135 \\
\hline Grocery shopper & -1.814995 & 0.5739459 & -0.4188678 & -3.16 & 0.002 \\
Sick as a result of unsafe chicken consumption & -1.119034 & 1.037501 & -0.1891969 & -1.08 & 0.281 \\
\hline WTP prices & -0.0002588 & 0.0001295 & -0.0005547 & -2.00 & 0.046 \\
Income & 0.5215385 & 0.294642 & 0.1117572 & 1.77 & 0.077 \\
\hline Risk averse & 0.2529825 & 0.8830985 & 0.0559509 & 0.29 & 0.775 \\
Risk neutral & -0.2368356 & 0.7465656 & -0.0517493 & -0.32 & 0.751 \\
\hline Intercept & 0.4745758 & 3.742511 & & 0.13 & 0.899 \\
\hline
\end{tabular}

LR Chi $^{2}=31.91 ;$ Prob > chi ${ }^{2}=0.0025 ;$ Log likelihood $=-61.740577 ;$ Pseudo $\mathrm{R}^{2}=0.3053$ 
http://faostat.external.fao.org/default (accessed October 2012).

\section{References}

Adeyonu AG, Oyawoye EO, Otunaiya AO, Akinlade RJ, 2016. Determinants of poultry farmers' willingness to participate in the National Agricultural Insurance Scheme in Oyo State, Nigeria. Appl Tropical Agriculture 21:55-62.

Akunyeli D, 2008. Highlights of the National Agency for Food and Drug Administration and Control. WIKIPEDIA. The free Encyclopedia. Available from: https://en.wikipedia.org/wiki/National_ Agency_for_Food_and_Drug_Adminis tration and Control Accessed: Mi chiedo come abbia fatto a recuperare l'autore-il link l'ho aggiunto io

Annan-Prah A, Mensah AA, Akorli SY, Kumi-Dei ID, 2012. Slaughterhouses, animal slaughter and slaughter hygiene in Ghana. J Vet Adv 2:189-98.

Bansback B, 2014. Future directions for the global meat industry. Wiley online library https://doi.org/10.1111/1746692X.12056

Bard SK, Barry PJ, 2000. Developing a scale for assessing risk attitudes of agricultural decision makers. Int Food Agribus 3:9-25.

Berges M, Casellas K, Rodrigues R, Errea D, 2015. Willingness to pay for quality attributes of fresh beef: implication on retailing marketing. International Conference of Agricultural Economists. Rome, Italy: Portal de Promoción y Difusión.

Central Bank of Nigeria (CBN), 2010. Statistical Bulletin Vol. 21, December 2010 .

Ehirim NC, 2010. Determinants of consumers' preference for safe chicken consumption in Imo State, Nigeria. 2:42-50. (ISSN: 1553-9865). http://www.sciencepub.net.

FAO, 2009. Nigeria nutrition profile, nutrition, and consumer protection division.
FAO, 2010. Livestock Report 2010, Rome 2010. Meat and Meat Products: Sources of Meat. Agriculture and Consumer Protection

FAO, WFP, IFAD, 2012. The State of Food Insecurity in the World 2012. Economic growth is necessary but not sufficient to accelerate the reduction of hunger and malnutrition. Rome, FAO. https://digitalcommons.1su.edu/gradschool_the$\operatorname{ses} / 810$ Drug Administration Amendments Act (FDAAA) 2007

Fatuase A, Ajibefun I, 2014. Perception and adaptation to climate change among farmers in selected communities of Ekiti State, Nigeria. J Agricultural Faculty of Gaziosmanpasa University 3:101-14.

Haenemann M, 1989. Welfare evaluation in contingent valuation experiment with discrete responses data. Am J Agricult Econ 71:1057-61.

Iyiola O, Oni-Ojo EE, 2013. Attitudes toward service innovations in the red meat industry and its consumption effects on Nigerian consumers. Developing Country Studies 3:22-49.

Knowles LL, Carstens BC, Keat ML, 2007. Coupling genetic and ecological-niche models to examine how past population distributions contribute to divergence. Current Biol 17:940-6.

Lacaze V, Rodriguez E, Lupin B, 2009. Risks Perceptions and Willingness-toPay for Organic Fresh Chiken in Argentina. Contributed Paper Prepared for Presentation at the International Association of Agricultural Economists Conference, Beijing, China, 16-22 August, 2009.

LaMarca N, 2011. The Likert Scale: Advantage and Disadvantages. Field Research in Organizational Psychology. Available from: https://psyc450.wordpress.com/2011/12/05/the-likert-scale-
FDA of the United States, 2007. Food and advantages-and-disadvantages/amp/.

Munene CN, 2006. Analysis of consumer attitudes and their willingness to pay for functional foods in 2006. LSU Master's Theses. 810.

Ogundipe A, Olurinola I, Odebiyi J, 2015. Examining the validity of EKC in Western Africa: different pollutants option. Environmental Management and Sustainable Development 4:1-22. 10.5296/emsd.v4i2.7076.

Pattison M, McMullin P, Bradbury JM, Alexander D, 2007. Poultry diseases. 6th Edition, Philadelphia: Elsevier Health Sciences.

Whittington D, Briscoe J, Mu X, Barron W, 1990. Estimating the willingness to pay for water services in developing countries: A case study of the use of contingent valuation surveys in southern Haiti. Economic development and cultural change 38:293-311.

Woolverton AE, Frimpong S, 2013. Consumer Demand for Domestic and Imported Broiler Meat in Urban Ghana: Bringing Non-Price Effects into the Equation. Br J Market Studies 1:16-31.

WHO, 2019. Food Safety Fact Sheets. https://www.who.int/news-room/factsheets/detail/food-safety. Accessed: November 8, 2019

Xiang BI, Lisa H, Zhifeng G, Fred G, 2012. Sensory Evaluation and Experimental Auctions: Measuring Willingness to Pay for Specific Sensory Attributes. Am J Agricult Econ 94:562-56

Yusuf R, 2011. Consumer willingness to pay for poultry products from biosecure farms in Bali. 55th National Conference of the Australian Agricultural and Resource Economics Society. Melbourne, Australia.

Zeru K, Kumie A, 2007. Sanitary conditions of food establishments in Mekelle town, Tigray, North Ethiopia. Ethiopian J Health Develop 2:1-9. 